\title{
Inhibition of renal glucose reabsorption as a novel treatment for diabetes patients
}

\author{
Inibição da reabsorção renal de glicose como uma nova forma de \\ tratamento para pacientes com diabetes
}

\begin{abstract}
Autores
Eugenio Cersosimo ${ }^{1}$

Carolina Solis-Herrera ${ }^{1}$

Curtis Triplitt ${ }^{1}$
\end{abstract}

1 University of Texas Health Science Center San Antonio, Texas.

Data de submissão: 30/11/2013 Data de aprovação: 06/01/2014

\section{Correspondência para:} Eugenio Cersosimo. Associate Professor of Medicine, Medical Director for Clinical Research, Texas Diabetes Institute. 7703 Floyd Curl Drive, MC 7886 San Antonio, TX, USA. 78229-3900.

E-mail: cersosimo@uthscsa.edu eugenio.cersosimo@uhs-sa.com Phone: 1 (210) 5676691 or (210) 3587200 . Fax: 1 (210) 3587235.

DOI: 10.5935/0101-2800.20140014

\section{Abstract}

The importance of the kidney in glucose homeostasis has been recognized for many years. Recent observations indicating a greater role of renal glucose metabolism in various physiologic and pathologic conditions have rekindled the interest in renal glucose handling as a potential target for the treatment of diabetes. The enormous capacity of the proximal tubular cells to reabsorb the filtered glucose load entirely, utilizing the sodium-glucose co-transporter system (primarily SGLT-2), became the focus of attention. Original studies conducted in experimental animals with the nonspecific SGLT inhibitor phlorizin showed that hyperglycemia after pancreatectomy decreased as a result of forced glycosuria. Subsequently, several compounds with more selective SGLT-2 inhibition properties ("second-generation") were developed. Some agents made it into pre-clinical and clinical trials and a few have already been approved for commercial use in the treatment of type 2 diabetes. In general, a 6-month period of therapy with SGLT2 inhibitors is followed by a mean urinary glucose excretion rate of $\sim 80 \mathrm{~g} / \mathrm{day}$ accompanied by a decline in fasting and postprandial glucose with average decreases in $\mathrm{HgA} 1 \mathrm{C} \sim 1.0 \%$. Concomitant body weight loss and a mild but consistent drop in blood pressure also have been reported. In contrast, transient polyuria, thirst with dehydration and occasional hypotension have been described early in the treatment. In addition, a significant increase in the occurrence of uro-genital infections, particularly in women has been documented with the use of SGLT-2 inhibitors. Conclusion: Although long-term cardiovascular, renal and bone/mineral effects are unknown SGLT-2 inhibitors,

\section{Resumo}

A importância do rim na homeostase de glicose é reconhecida desde há muitos anos. Observações recentes, indicando um papel maior do metabolismo renal da glicose em várias condições fisiológicas e patológicas, reavivaram o interesse no manuseio renal de glicose como um alvo em potencial para o tratamento do diabetes. A enorme capacidade das células tubulares proximais para reabsorver a carga total de glicose filtrada, utilizando o sistema de co-transporte de sódio e glicose (SGLT), tornou-se o foco de atenção. Estudos originais realizados em animais experimentais com o uso do inibidor não-específico da SGLT florizina, demonstraram que a hiperglicemia após pancreatectomia diminuiu como resultado de glicosúria forçada. Posteriormente, foram desenvolvidas diversas substâncias com propriedades mais seletivas de inibição da SGLT-2 ("segunda geração"). Vários agentes foram usados em ensaios pré-clínicos e clínicos, e alguns já foram aprovados para uso comercial no tratamento da diabetes tipo 2 . Em geral, os dados clinicos mostram que um período de 6 meses de tratamento com inibidores da SGLT-2 é seguido por uma taxa de excreção de glicose urinária média de $\sim 80 \mathrm{~g} / \mathrm{dia}$, acompanhado por uma queda na glicemia de jejum e pós-prandial e com redução média na HbA1C de $-1.0 \%$. Também foram relatados perda concomitante no peso corpóreo e uma leve mas consistente queda da pressão arterial. Em contraste, eventos adversos transitórios como poliúria, sede com desidratação e hipotensão ocasional foram descritos na fase inicial de tratamento. Além disso, um aumento significativo na ocorrência de infecções urogenitais, particularmente em mulheres, foi documentado com o uso de inibidores da SGLT-2. Os efeitos cardiovasculares, renais e ósseo/minerais a longo prazo destes agentes ainda são desconhecidos. Conclusão: Os inibidores da SGLT-2, se usados de forma criteriosa e em pacientes adequados, representam uma opção terapêutica única, que explora um 
if used with caution and in the proper patient provide a unique insulin-independent therapeutic option in the management of obese type 2 diabetes patients.

Keywords: diabetes mellitus, type 2/therapy; glycosuria; kidney, sodium-glucose transporter 2. novo mecanismo de ação anti-hiperglicêmico independente da insulina. Estão portanto indicados, tanto na monoterapia ou em combinação com outros agentes no tratamento de pacientes obesos com diabetes tipo 2 .

Palavras-chave: diabetes mellitus tipo 2/terapia; glicosúria; rim; transportador 2 de glucose-sódio.

\section{INTRODUCTION}

The importance of the kidney in glucose homeostasis has been recognized for many years. ${ }^{1,2}$ A critical observation indicating that the renal contribution to glucose regulation and counter-regulation might perhaps be of greater significance than previously anticipated was reported in the early 1990's. ${ }^{3}$ This publication rekindled the interest in the role of the kidney in glucose metabolism and several studies in animals ${ }^{4-6}$ and humans ${ }^{7-10}$ subsequently demonstrated the potential impact of renal glucose handling in various physiologic and pathologic conditions. Concomitantly, the pharmacological development of new agents capable of inhibiting renal glucose reabsorption was accelerated and has now reached clinical relevance. As a result, the kidney has become an additional target for anti-diabetic medications.

Renal glucose handling includes free glomerular filtration with complete proximal tubular reabsorption into the renal interstitial fluid space. Renal gluconeogenesis that takes place in the proximal tubular cells adds a small fraction to the glucose load that exchanges with the peri-tubular capillaries along the proximal nephron. In the distal nephron, glucose extracted can be either stored in the form of glycogen or oxidized to generate energy. In turn, no glucose is excreted in the urine and nearly all filtered glucose load perfusing the distal nephron is restored to the peripheral circulation, after mixing in the renal vein with the remainder $80 \%$ of unfiltered blood. ${ }^{11}$

The evidence for the heterogeneity of glucose handling within the nephron (Figure 1) is substantiated by numerous reports in the literature. ${ }^{1,12-15}$ Several studies have defined the molecular structure and the enormous enzymatic and transport capacity of the renal tubules. The sodium-glucose co-transport system (SGLT) is located at the luminal membrane of the proximal renal tubular cells. ${ }^{15}$ These cells contain specific enzymes that enable glucose synthesis de novo [renal gluconeogenesis], ${ }^{1,12}$ although no enzymatic activity for concomitant glucose utilization, storage or oxidation has ever been identified in proximal tubules. ${ }^{14}$

Figure 1. Schematic representation of the nephron showing the heterogeneity of glucose handling by the kidney. Plasma glucose is freely filtered at the glomerulus and completely reabsorbed in the proximal tubules. The SGLT-2 transporters located at the luminal membrane of cells in the S1 and S2 segments are responsible for $90 \%$ of total glucose re-uptake. The SGLT-1 transporters located downstream in the S3 segment of the proximal tubules account for the remainder $10 \%$ of the glucose load reabsorbed into the renal interstitial fluid. The process of renal gluconeogenesis occurs exclusively in the proximal tubular cells, whereas glucose utilization is limited to the distal nephron. Glycogen synthesis and storage, as well as complete glucose oxidation are detected only in cells of the distal nephron and, partial oxidation (anaerobic glycolysis) with formation and release of lactate is a characteristic of the hypoxic medullary regions of the kidney.

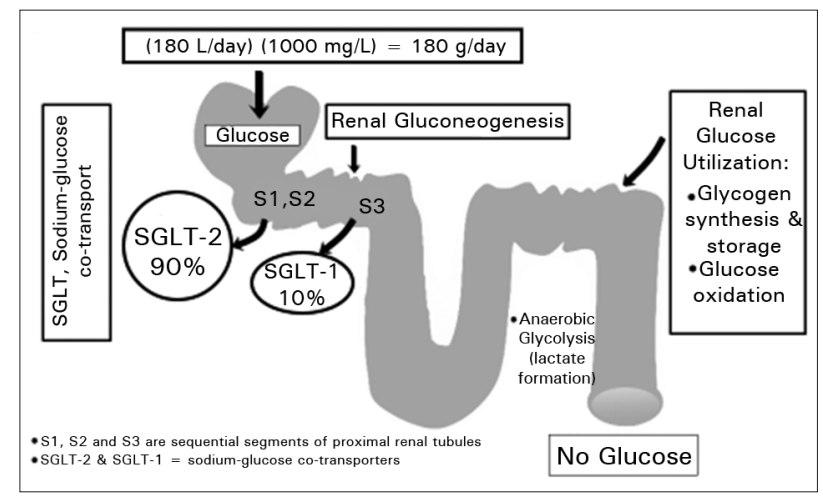

In contrast, the distal nephron has sufficient biochemical capability to metabolize the glucose extracted from the peri-tubular fluid and, the renal medulla is in fact an obligatory site for glucose oxidation. ${ }^{13,14}$ Because most of the energy required by the mega-transport tubular activity is supplied primarily from the oxidation of fatty acids, glucose sparing by the kidney is enabled and represents a critical aspect in the maintenance of whole-body glucose homeostasis.

\section{RENAL GLUCOSE TRANSPORT AND METABOLISM}

Various glucose transmembrane transport systems and intracellular metabolic pathways have been well characterized in the kidney. Most information is derived from in vitro cell preparations ${ }^{16-18}$ and renal perfusion studies using experimental animal models. ${ }^{19-21}$ Analogous 
findings have been reported in a few studies conducted in human kidney. ${ }^{22,23}$ Glucose is actively transported from the lumen to the tubular cells essentially by two transmembrane proteins: one with high capacity-low affinity termed sodium-glucose transport SGLT-2 and a second with high affinity-low capacity transporter termed SGLT-1. The SGLT-2 is found in the earlier S1 and S2 segments of the proximal tubule and the SGLT-1 in the $\mathrm{S} 3$ segment of the proximal tubules, ${ }^{15,17}$ which is also abundant in the enterocytes of the intestinal mucosa. ${ }^{21}$

Considering that nearly 180 liters of plasma are filtered daily by the kidneys with plasma glucose concentrations ranging between $80-120 \mathrm{mg} / \mathrm{dl}$ (an average of $100 \mathrm{mg} / \mathrm{dl}$ ), the glucose load that crosses the glomeruli is estimated to be around 180 grams per day (Figure 2). Circulating glucose is neither protein-bound nor attached to macromolecules and thus, is freely filtered at the glomerulus. The ultrafiltrate carries the glucose towards the luminal side of the early S1 segment in the proximal tubules, where SGLT-2 is located. The active process of re-uptake of glucose is coupled with the transport of sodium cations and the complex is transferred to the cell membrane at the level of the $\mathrm{S} 1$ segment.

Figure 2. Diagram of a proximal tubular cell located in the S1 segment with transport activity and metabolic pathways leading to effective sodium-glucose reabsorption and gluconeogenesis. Glucose coming from the glomerular filtrate enters the urine lumen, couples with sodium ions and binds avidly to the high capacity-low affinity (Km 6.0 $\mathrm{mM}$ ) SGLT-2 transporter. The energy required to actively transport the sodium-glucose complex into the cell is supplied by ATP generated by the sodium-potassium ATPase pump action, located in the baso-lateral membrane. Proximal tubules utilize primarily fatty acid oxidation to meet their energy demands and are not capable of metabolizing glucose. Thus, glucose reaches the baso-lateral cell membrane intact, where the GLUT-2 transporter promotes a facilitated passive transport, in favor of a glucose concentration gradient. Gluconeogenesis occurs from precursors such as amino acids, lactate and glycerol arising in the urine lumen via active tubular transport. The presence of the enzyme glucose-6-phosphatase enables de-phosphorylation of newly formed glucose-6-phosphate and glucose is also released into the interstitial fluid, via GLUT-2 facilitated transport. The sodium and glucose-rich proximal interstitial fluid exchanges with blood in the peri-tubular capillaries and perfuses the distal nephron.

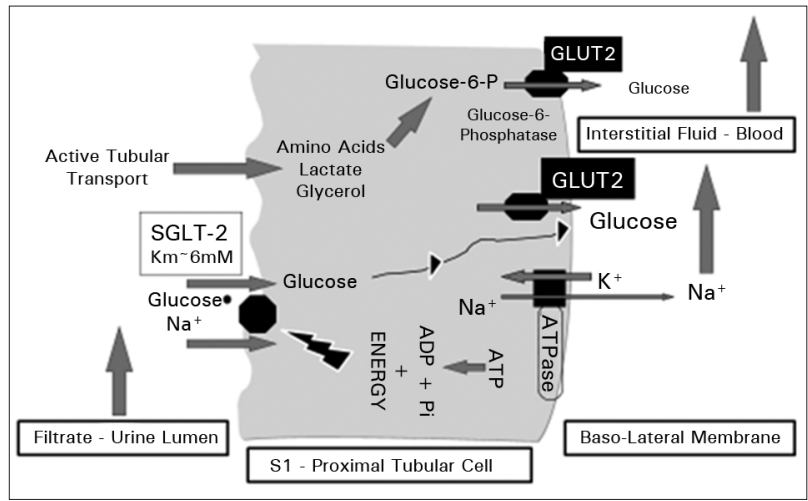

This same system is also utilized to carry amino acids from the lumen into the proximal tubular cells. The SGLT-2 transport activity across the luminal membrane is driven by an electro-chemical gradient, which is created by the action of the ATPase-mediated sodium-potassium pump located in the baso-lateral membrane of the cells. ${ }^{21}$ The energy consumed in this active transport process is supplied entirely from ATP derived the oxidation of intracellular fatty acids. ${ }^{11}$ As glucose builds up inside the proximal tubular cells, a facilitated passive transport in favor of a concentration gradient and mediated by GLUT-2 transporters, transfers intact glucose molecules out and into the surrounding renal interstitial fluid. ${ }^{24}$ In addition to restoring glucose (and amino-acids) to the interstitial fluid and eventually to the peripheral circulation, this sodium co-transport process also contributes to the maintenance of fluid and electrolyte balance by the kidney. ${ }^{15}$

In physiologic conditions the high capacity of the SGLT-2 co-transport system is responsible for the reabsorption of nearly $90 \%$ of all filtered glucose load. The re-uptake of the remainder $10 \%$ of the glucose load is a function of the low-capacity-high affinity SGLT-1 co-transporter and takes place downstream in the S3 segment of the proximal tubules. It is of interest however that despite its minor contribution to glucose re-uptake in the kidney, SGLT-1 represents a major mechanism via which glucose and galactose derived from the meals are absorbed in the intestines. ${ }^{20,21}$

On the other hand, the fact that SGLT-2 is exclusively found in the proximal tubules of the kidney, as opposed to SGLT-1 or GLUT-2, makes this transporter suitable for more specific renal pharmacologic interventions. Thus, the possibility of interfering with the activity of the SGLT-2 has become of considerable clinical significance. It should be emphasized that there is a minor contribution to the glucose load released into the interstitial fluid provided by the process of renal gluconeogenesis. ${ }^{1,3,6}$

This is possible because proximal tubular cells contain the enzymes necessary to synthesize glucose de novo, including glucose-6-phosphatase, the last step which enables newly-formed glucose to be de-phosphorylated and then secreted into the extra-cellular space. ${ }^{14}$ The fact that there is no detectable biochemical capacity in the proximal tubular cells to either utilize or store glucose, enables the entire filtered glucose load to be released unaffected 
into the renal interstitium. Thus, together with the small fraction of newly-synthesized glucose added by the proximal tubules the glucose-rich interstitial fluid exchanges with the renal venous capillaries and reaches the renal vein.

Unlike the proximal nephron, cells in the distal nephron are fully capable of glucose utilization. In physiologic conditions, the amount of glucose utilized in the distal segments of the nephron equals that derived from the renal gluconeogenesis in proximal tubules. This is confirmed by the common finding that the arterial-renal vein blood glucose concentration difference in the post-absorptive state is near zero. This is not the case however in more prolonged fasting conditions and during hypoglycemia, when a net contribution of the kidney to systemic glucose appearance has been demonstrated..$^{7-9,25,26}$ The glucose extracted in the distal nephron is directed either towards glycogen synthesis for storage or to oxidative pathways, depending upon the local energy demands. Whether this glucose uptake is mediated via an insulin-dependent mechanism or a facilitated transport still remains controversial., 3 ,7-9

Renal glycogen accumulation is thought to provide for immediate local energy needs, when blood-borne glucose supply lags behind. The renal oxidation of glucose can be partial (anaerobic glycolysis) with the release of lactate and ATP, or complete, a mitochondrial process that yields $\mathrm{H}_{2} \mathrm{O}, \mathrm{CO}_{2}$ and ATP. Partial anaerobic glucose oxidation is more prevalent in hypoxic medullary renal conditions. ${ }^{12-14}$ Renal glucose utilization occurs exclusively in distal tubular cells and, in the absence of glucose-6-phospatase activity no glucose is released back into the interstitial fluid. ${ }^{14}$ Moreover, the small amount of glucose utilized distally does not affect the total glucose load leaving the nephron into the renal veins.

\section{GLUCOSE HANDLING BY THE KIDNEY}

The fate of the glucose filtered, reabsorbed and excreted in the urine in normal and hyperglycemic conditions depends upon the glomerular filtration rate, the prevalent plasma concentration of glucose and the total transport capacity of the proximal tubules (Figure 3). There is a linear relationship between the filtered glucose load at the glomerulus and plasma glucose and thus, the glucose appearance in the ultrafiltrate will be higher or lower as plasma glucose concentration increases or decreases, respectively.
Figure 3. This graph summarizes the urinary glucose excretion and the renal threshold TMG values ("splay") calculated in normal healthy individuals (dotted line) and in patients with diabetes prior to and following the administration of SGLT-2 inhibitors (solid lines). The vertical axis expresses urinary glucose excretion rates in grams per day and the horizontal axis represents venous plasma glucose concentrations in $\mathrm{mg} / \mathrm{dl}$. Note that in patients with diabetes there is an elevated renal threshold ( $T m G)$ that is substantially reduced by the effect of SGLT-2 inhibitors.

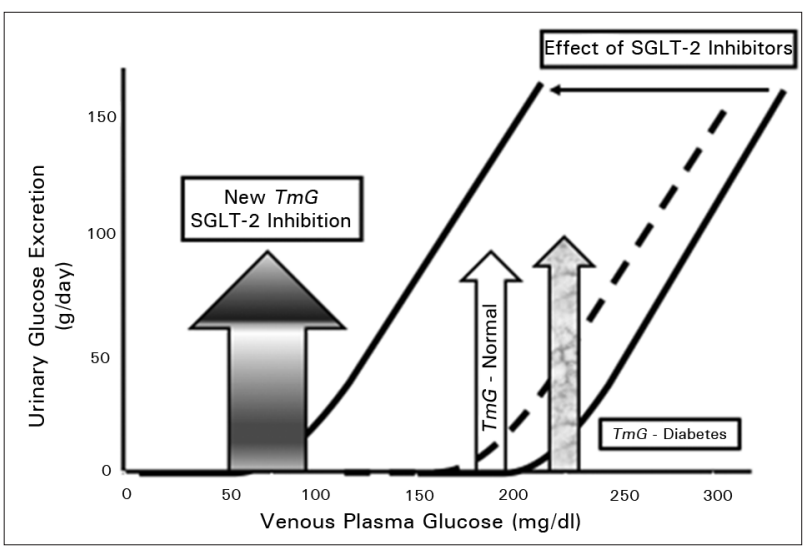

To a lesser extent, the same is true for bi-directional changes in the glomerular filtration rate. The proximal tubular reabsorption rate, on the other hand is only linear with the glucose load reaching the luminal membrane within a "normal" glycemic range. Once the maximum tubular reabsorption capacity of the kidney (Tmax,) is attained the transport process becomes saturated and glucose spills into the urine. It is worth mentioning that since the Tmax for glucose varies considerably among the nearly 2 millions nephrons in both kidneys, the maximum transport capacity is actually a "splay" or a range of values estimated to be around the calculated Tmax. ${ }^{21,27,28}$

The "splay" is derived as the rounding of the curves for maximum glucose reabsorption and excretion rates, which show a non-linear transition as the Tmax value is approached. The Tmax can be determined by artificially elevating plasma glucose levels in a stepwise fashion up to $400-500 \mathrm{mg} / \mathrm{dl}$ with simultaneous measurements of the glomerular filtration rate, plasma and urine glucose concentrations, and urine output at given intervals. In individuals with normal kidney function, the calculated maximum tubular glucose transport has been reported between 350-450 $\mathrm{mg} / \mathrm{min}$, which corresponds to mean mean venous glucose concentration in the range of $180-200 \mathrm{mg} / \mathrm{dl}$.

Hence, the normal renal threshold $(\operatorname{Tm} G)$ is often referred to as the venous plasma glucose concentration $\sim 180 \mathrm{mg} / \mathrm{dl} .{ }^{27}$ Once this value is exceeded the SGLT system saturation transport capacity is 
passed and glycosuria ensues. $\operatorname{Tm} G$ varies with changes in glomerular filtration rates such that during pregnancy or with a unilateral kidney, when glomerular filtration rates increase, glucosuria will occur at plasma glucose concentrations below $180 \mathrm{mg} / \mathrm{dl}$ (lower TmG). Conversely, when glomerular filtration decreases such as in chronic kidney disease, glucosuria is seen at plasma glucose levels higher than $220 \mathrm{mg} / \mathrm{dl}^{27,28}$ Of additional interest, some apparently healthy individuals inherit a genetic abnormality characterized by a defective SGLT transport system and thus, have constant glycosuria with normal glomerular filtration rates and in conditions of normoglycemia. ${ }^{29}$

The observation that the maximum tubular glucose reabsorption rate and the saturation capacity are markedly affected by chronic hyperglycaemia ${ }^{22,30,31}$ has provided the basis for a novel approach in the treatment of diabetes. Exposure to hyperglycemia is reportedly accompanied by an increase in tubular $\operatorname{Tm} G$, reflecting enhanced maximum glucose transport capacity and reabsorption. As a consequence, the appearance of glucose in the urine tends to occur at plasma glucose concentrations above the normal renal threshold of $180-200 \mathrm{mg} / \mathrm{dl}$ in patients with diabetes.

This adaptation was first reported by Farber $e t$ al. in 1951 who showed that the "splay" for maximal glucose reabsorption (Tmax) was expanded and the renal threshold augmented in patients with type 2 diabetes by $20-40 \%{ }^{30}$ Two decades later, Morgensen ${ }^{22}$ described similar findings in patients with type 1 diabetes. More recent data derived from in vitro studies using cultures of proximal renal tubular cells collected from urine samples of subjects with and without diabetes fully supported these observations. In these experiments proximal tubular cells from patients with diabetes were shown to have increased mRNA expression and SGLT-2 protein content. Moreover, using a radio-labelled glucose analogue functional assay these cells also exhibited an elevated glucose transport capacity. ${ }^{31}$ Altogether, these results were interpreted as an indication that there is a maladaptive response of the kidney to hyperglycemia in diabetes mellitus. It has been speculated that by increasing glucose reabsorption rates, the kidney helps to maintain the abnormal status of hyperglycemia, which may in turn lead to further maladaptation.

\section{INHIBITORS OF TUBULAR GLUCOSE REABSORPTION}

The possibility that the diabetic kidney perpetuates hyperglycemia gave rise to the notion that agents capable of inhibiting renal glucose reabsorption might be useful in lowering blood glucose. ${ }^{32-34}$ As originally envisioned, SGLT inhibitors would reduce the tubular capacity for glucose reabsorption and promote glucosuria at lower plasma glucose levels (low Tm glucose). This hypothesis was tested with phlorizin, a compound extracted from the root bark of apple tree with presumed anti-diabetic properties due to its known in vitro inhibition of tubular glucose transport.

In 1987, Rosettti et al. ${ }^{32}$ published data indicating that hyperglycemia, which developed in the fasting and fed state in rats after partial pancreatectomy, could be reversed with once daily intra-peritoneal injection of phlorizin. Following the discontinuation of the injections hyperglycemia was again detected, thus confirming that phlorizin was responsible for the improvement. These findings suggested that with adequate chemical blockade of the SGLT transport activity, the renal threshold for glucose reabsorption could be decreased and better glycemic control achieved in patients with diabetes.

Although there was some excitement surrounding these findings, the lack of selectivity of phlorizin, the associated adverse gastro-intestinal effects and the uncertainty regarding the consequences of the induced glucosuria dampened the initial enthusiasm for the clinical development of this agent. Furthermore, the realization that phlorizin was quickly degraded by lactase-phlorizin hydrolase, was poorly absorbed in the intestines and had very low bioavailability further halted any investigation using this nonspecific SGLT inhibitor in humans. ${ }^{34}$

A search for SGLT-2 inhibitors that were more selective and more resistant to intestinal degradation and had higher plasma bioavailability was launched. Many agents with SGLT inhibitor properties were obtained by techniques capable of chemically modifying the parent compound phlorizin ("second generation agents"). Initially in vitro experiments in cultured cell lines expressing human SGLT-1 and SGLT-2 transporters were conducted to determine the degree of selectivity of any given SGLT inhibitor using radio-ligand binding assays. ${ }^{35-37}$

Following a series of investigations a high degree of selectivity inhibition of SGLT-2 was initially shown for "empagliflozin" (L-chloro-4-( $\beta$ D-glycopyranos-1-Yl)-2-[4-((S)-tetrabydrofuran3-Yl-oxy)-benzyl-benzene). Numerous other compounds were tested in a similar fashion and in vivo 
animal studies confirmed that these "second generation" agents were minimally degraded in the intestines and were only subject to a mild-to-modest total plasma clearance. Adequate bioavailability in the range of 33 to $80 \%$ was documented for most of these "second-generation" compounds developed. ${ }^{35-37}$

The specificity of some of these agents in vivo was questioned by the recent findings in humans revealing that orally ingested selective SGLT-2 inhibitors must first interact with the SGLT-1 transporters at the brush-border membrane of enterocytes. ${ }^{38}$ Because the enterocytes containing the SGLT-1 transporters are exposed to a greater load of the SGLT-2 specific inhibitors inside the gut, the binding affinity and thus, the selectivity is lost. As a result, the activity of the sodium-glucose/galactose co-transport process as a whole is reduced and there is a transient decline in the intestinal absorption of these sugars. The selectivity for the renal SGLT-2 transporters is nevertheless regained after partial splanchnic clearance and with lower circulating plasma drug levels.

Once selective inhibitors reach the kidney via the systemic arterial blood circulation, they bind avidly to SGLT-2 transporters in the luminal tubular membrane. In contrast, at much lower concentrations the binding affinity of these agents for the SGLT-1 transporter located downstream in the same area is severely diminished and no inhibition of the SGLT-1 activity in the kidney is detected. ${ }^{35}$ Following an insulin-independent decline in blood glucose, SGLT-2 inhibition is also accompanied by mild improvement in insulin sensitivity, ${ }^{38,39}$ which represents an additional mechanism by which these agents contribute to glycemic control in patients with type 2 diabetes. Moreover, recent findings reported in a SGLT-2 knockout mouse model provide evidence for an alternative approach to improving glycemic control and reducing insulin sensitivity with preservation of beta-cell function, by simply reducing the renal threshold and promoting renal glycosuria. ${ }^{40}$

\section{Clinical PHARMACOLOGY AND PHARMACOKINETICS}

The maximum inhibitory effect achievable on the renal glucose re-uptake with the use of selective blockade of the tubular SGTL-2 transporter activity in humans has been reported at 30-50\%. ${ }^{41,42}$ It has been postulated that the efficacy of these agents is somewhat limited, in part because of the competitive nature of the inhibitory binding process. There is also the possibility that very low levels of the active drug reach the tubular luminal membrane, the main site of the drug action. Finally, and perhaps most importantly, the extent to which a compensatory enhancement in the glucose reabsorption capacity of the SGLT-1 co-transporter or by a yet unidentified tubular glucose transport system, located downstream contributes to the low effectiveness of these agents has not been defined. ${ }^{15,19}$ Once plasma steady-state concentrations of the SGLT inhibitor are reached (4 to 5 days), the total amount of glucose excreted in the urine is around 50-80 grams per day. This results from the partial blockade of the SGLT-2 co-transporter and reflects a shift to the left in the maximum tubular transport capacity with a substantial decrease in the renal threshold $[\operatorname{Tm} G] .^{38,41}$

Clinical observational studies conducted in healthy non-diabetic and in diabetic subjects have indicated that the appearance of glucosuria can be detected within 8-16 weeks after the oral intake of the first dose of an SGLT-2 inhibitor. ${ }^{43,44}$ Actually, it has been estimated that following a short therapy period with SGLT-2 inhibitors glucosuria can be detected both in subjects with and without diabetes at plasma glucose values ranging anywhere from $40-120 \mathrm{mg} / \mathrm{dl} .^{38}$ This remarkable shift in the renal threshold for glucose reabsorption contributes to a significant decrease in circulating plasma glucose, which is accomplished with a daily loss of 200-320 calories.

These changes combined can provide much desired benefits for obese patients with diabetes. The decline in plasma glucose concentration following the use of SGLT inhibitors has been recently reported to be attenuated by a rise in plasma glucagon accompanied by an elevation in endogenous glucose production. ${ }^{39,45}$ These findings were documented in subjects who had received SGLT-2 inhibitors for a short period of time and who had experienced a drop in plasma glucose levels, but with no evidence of hypoglycemia. These intriguing observations have raised new questions regarding potential interactions of the kidney and liver in glucose regulation and counter-regulation, and will require confirmation.

Following oral administration SGLT-2 inhibitors are rapidly absorbed with peak plasma 
concentrations (median $T_{\max }$ ) occurring 1-2 hours post-dose. Plasma $C_{\max }$ and the area under the curve $(A U C)$ increase in a dose-proportional manner with apparent terminal half-life $\left(t_{1 / 2}\right)$ of varying from 10 up to 13 hours. The active drug reaches a steady-state usually within 4 to 5 days. ${ }^{37,38,41}$ The major metabolic elimination of SGLT-2 inhibitors is via hepatic glucuronidation and the inactive metabolites are released into peripheral circulation. There is minimal CYP3A4-mediated oxidative metabolic degradation. Thus, clinically relevant effects of other drugs on the pharmacokinetics of SGLT-2 inhibitors via cytochrome P450 are unlikely to occur. Also, since the CYP450 enzyme system is not induced and is only minimally attenuated by SGLT-2 inhibitors only negligible changes in drugs utilizing the same hepatic metabolic processes have been reported.

In contrast, a decrease in total exposure to active SGLT-2 inhibitors occurs when UGT (glucuronosyl transferase) inducers, such as rifampin, phenytoin and phenobarbital are co-administered. Plasma digoxin levels tend to increase and require closer monitoring when used in combination with SGLT-2 inhibitors. When using oral radio-labeled SGLT-2 inhibitors in normal healthy volunteers nearly $50 \%$ of the active drug is recovered in feces together with minor amounts (less than $10 \%$ ) of some inactive metabolites; less than $1 \%$ of the oral dose is excreted intact in the urine. ${ }^{46}$

\section{SAFETY AND EFFICACY OF SGLT INHIBITORS}

The fact that selective inhibitors of SGLT-2 lower plasma glucose concentration via an insulin-independent manner, and thus with minimal risk of hypoglycemia, combined with the potential to induce simultaneous body weight loss has generated considerable clinical interest. ${ }^{47-51}$ Several SGLT-2 inhibitors are currently in development and some have already been approved for use in the treatment of patients with type 2 diabetes. Results from a few selected clinical trials are summarized on Table 1.

Most studies have shown consistent and unequivocal improvements in glycemic control in a variety of diabetic patients with a decline in both fasting and postprandial plasma glucose. The mean reported decrease in the glycosylated hemoglobin $\left(\mathrm{HbA}_{1 \mathrm{c}}\right)$ values was approximately $1.0 \%$, which was initially documented over a period of 6 months.
More recent preliminary data have confirmed that these changes can be sustained with safety up to 4 years. ${ }^{52}$ The degree of glycemic control attained with SGLT-2 inhibitors was shown to be either comparable or superior to anti-diabetic agents routinely recommended in standard practice..$^{49-51}$

The exact placement of SGLT-2 inhibitors in algorithms designed to guide management of diabetes remains undetermined and is likely to be somewhat controversial. ${ }^{53-55}$ These drugs are known to be effective as monotherapy and, even though the decrease in blood glucose can be attained within a wide range of plasma glucose concentration, whether early in the disease (or in pre-diabetes) the tubular reabsorption capacity is abnormally enhanced has not been fully determined. Moreover, with limited clinical experience and considering the added cost this class of drugs is more likely to be used later, rather than earlier in the treatment of type 2 diabetes. The possibility nevertheless of combining these agents with other well-established anti-diabetic drugs, oral and injectables seems more reasonable. Taking into account the unique mechanism of action of SGLT-2 inhibitors, maybe they are best if indicated in patients with poorly-controlled type 2 diabetes in whom oral treatment has been exhausted and the initiation of injectable agents or insulin replacement therapy is eminent.

These suggested therapeutic options are not based on firm scientific evidence and represent but one viewpoint. The ultimate decision as to when and how to best use SGLT-inhibitors during the course of diabetes treatment will require additional data as well as the experience acquired over a prolonged period of time.

Body weight loss was anticipated and has occurred in almost all diabetic patients who received therapy with SGLT-2 inhibitors in pivotal clinical trials. ${ }^{47-52}$ The usual amount of body weight lost was reported in the range of 2 to 4 kilograms over a period of observation of 6 months, with only a few outliers. Interestingly, studies using other drugs that promote body weight usually provide results with noticeable individual variability, whereas SGLT-2 inhibitors tend to induce nearly equal body weight loss in just about everyone treated. A recent study indicated that the majority of the weight reduction was due to the loss of body fat mass, $\sim 50 \%$ each in the abdominal and subcutaneous fat depots, with minimal changes in lean body mass. ${ }^{56}$ 


\begin{tabular}{|c|c|c|c|c|c|}
\hline TABle 1 & $\begin{array}{l}\text { RTED CLINICAL EFFICACY } \\
\text { MENT OF TYPE } 2 \text { DIABET }\end{array}$ & $\begin{array}{l}\text { F VARIOUS SGLT-2 } \\
\text { S }\end{array}$ & JHIBITORS USED IN & OTAL CLINICA & TRIALS IN THE \\
\hline SGLT-2 inhibitor & Placebo/comparator & Duration of study & Baseline $\mathrm{HbA}_{1 \mathrm{c}}$ & $\Delta \mathrm{HbA}_{1 \mathrm{c}}{ }^{\wedge}$ & 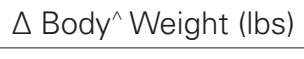 \\
\hline $\begin{array}{c}\text { Canagliflozin } \\
100 \mathrm{mg} \\
300 \mathrm{mg}\end{array}$ & vs. PLACEBO & 26 weeks & $\begin{array}{l}\sim 8.0 \% \\
\sim 8.1 \%\end{array}$ & $\begin{array}{l}-0.91 \% * \\
-1.16 \% *\end{array}$ & $\begin{array}{l}-4.2^{*} \\
-6.4^{*}\end{array}$ \\
\hline $\begin{array}{l}\text { Canagliflozin } \\
300 \mathrm{mg}\end{array}$ & $\begin{array}{l}\text { vs. SITAGLIPTIN (+ } \\
\text { MET \& SU) }\end{array}$ & 52 weeks & 8.1\% & $-0.37 \% * *$ & $-5.2^{*}$ \\
\hline $\begin{array}{c}\text { Canagliflozin } \\
100 \mathrm{mg} \\
300 \mathrm{mg}\end{array}$ & $\begin{array}{c}\text { vs. PLACEBO } \\
(+ \text { Insulin \& AHA) }\end{array}$ & 26 weeks & $\sim 8.3 \%$ & $\begin{array}{l}-0.69 \% * \\
-0.73 \% *\end{array}$ & $\begin{array}{l}-1.9^{*} \\
-2.4^{*}\end{array}$ \\
\hline $\begin{array}{l}\text { Dapaglifozin } \\
10 \mathrm{mg}\end{array}$ & $\begin{array}{l}\text { vs. MET alone } \\
\text { vs. COMBO }\end{array}$ & 24 weeks & 8.1\% & $\begin{array}{l}-1.44 \% \\
-1.98 \%\end{array}$ & $\begin{array}{l}-3.2^{@} \\
-4.8^{@}\end{array}$ \\
\hline $\begin{array}{l}\text { Dapaglifozin } \\
10 \mathrm{mg}\end{array}$ & vs. SU (+ MET) & 52 weeks & $\sim 7.7 \%$ & $-0.18 \% * *$ & $-2.5^{* *}$ \\
\hline $\begin{array}{l}\text { Dapaglifozin } \\
10 \mathrm{mg}\end{array}$ & vs. SU (+ MET) & $\begin{array}{l}208 \text { weeks } \\
\text { (4 years) }\end{array}$ & $\sim 7.7 \%$ & $-0.30 \% *$ & $-5.6^{*}$ \\
\hline $\begin{array}{c}\text { Empaglifozin\# } \\
5 \mathrm{mg} \\
10 \mathrm{mg} \\
25 \mathrm{mg} \\
\end{array}$ & vs. PLACEBO & 16 weeks & $\sim 7.9 \%$ & $\begin{array}{l}-0.24 \% \text { * } \\
-0.52 \% \text { * } \\
-0.50 \% \text { * }\end{array}$ & $\begin{array}{l}-3.0^{*} \\
-5.2^{*} \\
-4.8^{*}\end{array}$ \\
\hline $\begin{array}{l}\text { Ipraglifozin" } \\
50 \text { mg }\end{array}$ & vs. PLACEBO & 16 weeks & $\sim 8.3 \%$ & $-1.10 \% *$ & $-5.2^{*}$ \\
\hline
\end{tabular}

$\triangle \mathrm{HbA}_{1 \mathrm{c}}$ and $\triangle$ Body Weight: Represent mean values, degree variation not provided; $\wedge$ statistically significant with $p<0.05$, unless otherwise indicated (* $p$ values not available); * placebo-subtracted values; ** comparator-subtracted values; ${ }^{\circledR}$ changes from baseline.

The stabilization of the body weight achieved 6 months after the initiation of therapy, which has been confirmed to persist up to 4 years with the continued use of SGLT-2 inhibitors is regarded as a remarkable accomplishment and provides further reassurance to those who manage obese type 2 diabetic patients. ${ }^{52}$ Whether a later compensatory increase in appetite and/or a change in energy expenditure will occur in response to the loss of calories in the urine over longer periods of time should not be entirely discarded. As a reminder, these agents are not approved for the sole treatment of overweight and obese individuals who do not have a diagnosis of type 2 diabetes.

The low incidence of hypoglycemia is a clinically relevant and important characteristic associated with the use of SGLT-2 inhibitors in the management of type 2 diabetes. This results from the fact that the mechanisms underlying the glucose-lowering effect of a partial blockade of the tubular glucose re-uptake are insulin-independent and do not involve direct changes in insulin secretion.

Furthermore, the rate of urinary glucose excretion is proportionate to the circulating plasma glucose concentration (i.e., glucose-dependent glucose excretion) and thus, it becomes almost negligible in conditions of very low plasma glucose concentrations. In contrast, when SGLT-2 inhibitors are used in combination with insulin secretagogues (sulfonylurea, meglitinides) or together with insulin injections the risk for hypoglycemia is magnified. ${ }^{47-52}$ There is no current approved indication for the co-administration of SGLT-2 inhibitors with insulin therapy in type 1 diabetes, just as there are no data on the safety and efficacy of these agents in pediatric patients under 18 years of age.

Some important and a few unexpected findings have been reported in patients with type 2 diabetes who were exposed to various SGLT-2 inhibitors in clinical trials (Table 2). Following initial treatment a transient period (days to weeks) of polyuria, urinary frequency with increased thirst, often characterized as a simple state of dehydration was described in $3-5 \%$ of all study subjects. ${ }^{50,51}$ Two-thirds of these individuals had symptoms of postural dizziness and most of them had documented orthostatic hypotension. The majority recovered uneventfully, presumably because blood volume and fluid balance were appropriately corrected by alternate renal and some other mechanisms. Of note, dehydration and orthostatism was more common in elderly diabetic patients who were taking anti-hypertensive drugs and/or diuretics. 

TREATMENT OF TYPE 2 DIABETES

\begin{tabular}{|c|c|c|c|c|c|c|}
\hline SGLT-2 inhibitor & $\begin{array}{l}\text { Increased Urinary } \\
\text { Frequency }\end{array}$ & Increased Thirst & Hypotension & Hypoglycemia & $\begin{array}{l}\text { Urinary Tract } \\
\text { Infections }\end{array}$ & $\begin{array}{c}\text { Genital } \\
\text { Infections }\end{array}$ \\
\hline $\begin{array}{c}\text { Canagliflozin } \\
100 \mathrm{mg}(\mathrm{n}=3,092) \\
300 \mathrm{mg}(\mathrm{n}=3,085)\end{array}$ & $\begin{array}{l}174(5.6 \%) \\
177(5.7 \%)\end{array}$ & $\begin{array}{l}80(2.6 \%) \\
70(2.5 \%)\end{array}$ & $\begin{array}{l}20(<1.0 \%) \\
30(<1.0 \%)\end{array}$ & $\begin{array}{c}71(2.3 \%) \\
104(3.4 \%)\end{array}$ & $\begin{array}{l}171(5.5 \%) \\
175(5.7 \%)\end{array}$ & $\begin{array}{l}510(16.3 \%) \\
545(18.1 \%)\end{array}$ \\
\hline $\begin{array}{c}\text { Dapaglifozin } \\
5 \mathrm{mg}(\mathrm{n}=1,145) \\
10 \mathrm{mg}(\mathrm{n}=1,193)\end{array}$ & $1(<1.0 \%)$ & $1(<1.0 \%)$ & $\begin{array}{l}5(0.4 \%) \\
5(0.4 \%)\end{array}$ & $\begin{array}{l}25(2.2 \%) \\
35(3.0 \%)\end{array}$ & $\begin{array}{l}149(13.0 \%) \\
131(11.0 \%)\end{array}$ & $\begin{array}{l}155(13.5 \%) \\
181(15.1 \%)\end{array}$ \\
\hline $\begin{array}{l}\text { Empaglifozin } \\
10 \mathrm{mg}(\mathrm{n}=495)\end{array}$ & $12(2.5 \%)$ & $1(<1.0 \%)$ & N/A & $\mathrm{N} / \mathrm{A}$ & $19(4.0 \%)$ & 49 (10.0\%) \\
\hline $\begin{array}{c}\text { Ipraglifozin } \\
50 \mathrm{mg}(\mathrm{n}=62)\end{array}$ & $\mathrm{N} / \mathrm{A}$ & $\mathrm{N} / \mathrm{A}$ & $\mathrm{N} / \mathrm{A}$ & $\mathrm{N} / \mathrm{A}$ & $1(4.0 \%)$ & $2(<1.0 \%)$ \\
\hline
\end{tabular}

Despite the transient nature of these acute hemodynamic events, greater caution and a special attention to this vulnerable population will be required by prescribing physicians and health care providers. For reasons that are not entirely clear, a slight and consistent decrease in systolic and diastolic blood pressure has been recorded in nearly all diabetic patients treated with SGLT-2 inhibitors for at least 6 months. ${ }^{47-52}$

Whether this potential beneficial effect can be related to changes in blood volume and hydration status and/or to a direct or indirect vascular dilation property of SGLT-2 inhibitors remains undetermined.

Rare cases of mild hyperkalemia following the administration of SGLT-2 inhibitors have been reported, primarily in patients with some degree of renal insufficiency. ${ }^{57}$ Nearly all diabetic patients who experienced serum potassium elevations were using potassium-sparing diuretics, angiotensinconverting enzyme inhibitors or angiotensin receptor blocking agents. We speculate that by further altering the tubular-glomerular feedback loop with the reduction of the sodium-glucose reabsorption in proximal tubules these agents may exacerbate an underlying hyporeninemic-hypoaldosteronism state, commonly seen in type 2 diabetes. ${ }^{58}$ No serious clinical consequences however have yet been registered in association with hyperkalemia induced by SGLT-2 inhibitors.

Considering the recommendations for the use of SGLT-2 inhibitors are limited to lower doses and should be given only to diabetic patients with estimated glomerular filtration rate (eGFR) above $30 \mathrm{ml} / \mathrm{min} / 1.73 \mathrm{~m}^{2}$, the occurrence of hyperkalemia is expected to be a rare event. Because of pure inefficacy, these agents are not indicated in patients with advanced end-stage renal disease and those on renal dialysis. In case of inadvertent drug overdose and intoxication, SGLT-2 inhibitors cannot be removed from the circulation efficiently by hemodialysis. Almost nothing is known about untoward effects associated with acute elevations and tissue accumulation of the native SGLT-2 inhibitor compounds and their metabolites.

In patients with mild-to-moderate hepatic insufficiency, nonetheless there is no need for adjustments in dose, although the safety and efficacy of these SGLT-2 inhibitors have never been tested in patients with severe hepatic insufficiency. Also, the use of SGLT-2 inhibitors is contra-indicated during pregnancy and in lactating diabetic women, since newborn animals exposed to this agent exhibit a multitude of kidney and urogenital malformations. ${ }^{47}$

According to results from one large pivotal study presented earlier to the Food and Drug Administration (FDA) Advisory Committee, 9 cases of bladder cancer out of 5,501 patients $(0.16 \%)$ were reported in association with the use of dapagliflozin, as opposed to only one patient out of $3,184(0.03 \%)$ treated with placebo/comparator. ${ }^{47}$ During careful analyses of the data it was noted that all bladder cancers occurred in male patients and that 7 of all 10 patients with the diagnosis had had hematuria prior to the initiation of the study treatment. Furthermore, eight patients with bladder cancer were current or former smokers, five of them were diagnosed at $<6$ months from the start of dapagliflozin therapy, and none diagnosed with treatment longer than 24 months. In the same clinical 
trials, breast cancer developed in ten out of 2,531 women $(0.40 \%)$ treated with dapagliflozin $v s$. three out of 1,359 women $(0.22 \%)$ in the placebo/comparator groups. All breast cancers were recorded in female patients above the age of 50 years and, in fact 10 of 13 cases occurred in women above the age of 60 years.

The diagnosis was confirmed in women exposed to dapagliflozin for less than one year and in two cases the presence of breast cancer was documented within the first eight weeks of treatment. Based on these observations, the FDA concluded that there were too few events to establish causality, a decision supported by the fact that no carcinogenicity or mutagenic signal has been described during pre-clinical animal studies. Although the accumulation of large amounts of glucose in the bladder urine over time cannot be entirely rule out as a putative carcinogenic factor, it is reassuring to know that SGLT-2 transporter proteins are not expressed either in human bladder or in breast tissue. ${ }^{59}$

There was a noticeable increase in the incidence of urinary tract and genital infections in patients with type 2 diabetes who were treated with SGLT-2 inhibitors reported in all clinical trials. ${ }^{48-52}$ Nearly all infections were limited to the lower urinary tract and were reported in $\sim 8-13 \%$ of participants receiving SGLT-2 inhibitors, but only in $\sim 3-8 \%$ of those randomized to either placebo or a comparator drug. Similarly, genital infections developed in $~ 12-15 \%$ of patients taking SGLT-2 inhibitors, whereas those using placebo or a comparator drug had an incidence no higher than $\sim 5 \%$.

These observations were derived from studies that included more than 10,000 patients with type 2 diabetes followed by at least 2 years of exposure to various SGLT-2 inhibitors. ${ }^{47}$ Women, especially those with a positive past medical history were more commonly affected, although the vast majority of infections resolved with standard treatment, did not require hospital admissions, and recurrences were infrequent. Actually, many of the participants who developed urinary and genital infections elected to continue with the treatment, particularly those in whom glucose control and body weight loss were apparent. Less than $2 \%$ of all patients treated with SGLT-2 inhibitors who developed genital mycosis, namely balano-postitis, were uncircumcised men. ${ }^{47}$

Inasmuch as the potential for long-term adverse effects of SGLT-2 inhibitors on kidney function is unpredictable, we can take some comfort on the observations that individuals with "familial renal glucosuria" are essentially disease-free and live near-normal lives. ${ }^{60}$

This is an autossomal recessive disorder with either complete deficiency or decreased affinity for the SGLT-2 co-transporter protein. The genetics of "familial renal glucosuria" have been studied extensively and 21 different mutations in the gene for SGLT2 were detected. Homozygous individuals tend to have glycosuria that varies from 15 up to $200 \mathrm{~g} /$ day, whereas pure heterozygous family members have either mild glycosuria or none at all. Because this condition is characterized by persistent urinary glucose excretion, even within the normal range of plasma glucose concentration these individuals have difficulty maintaining body weight.

There is no evidence of renal glomerular or tubular dysfunction, as assessed by kidney function and renal histological evaluations. Hypoglycemia is uncommon and the incidence of diabetes mellitus, chronic renal insufficiency and urinary tract infections is comparable to the general population. The diagnosis of "familial renal glucosuria" must be distinguished however from other complex tubular disorders that can be associated with some morbidity ${ }^{60}$

There is no clinical evidence that the use of SGLT-2 inhibitors in patients with type 2 diabetes is associated with improved cardiovascular outcomes. A long-term trial is underway to address this question and we shall soon have an answer. In the meantime, the available data indicate that these drugs are cardiovascular safe and so far have not been accompanied by increases in cardiovascular events. ${ }^{47}$

The observation that there is a slight but consistent decrease in systolic and diastolic blood pressure sustained for up to 104 weeks contrasts with the slight elevation in plasma low-density lipoprotein (LDL) cholesterol particles described in most clinical studies, which makes it even more difficult to predict the final results of the ongoing cardiovascular outcomes trial.

In summary, the kidney plays an important role in glucose homeostasis, contributes to glucose regulation and counter-regulation, and in sparing glucose also helps to preserve the energy balance. These remarkable functions are achieved by an active proximal tubular mega-transport system that promotes complete glucose reabsorption and by the minimal intrinsic 
glucose production that often matches renal glucose utilization. Chronic hyperglycemia is associated with an increase in renal threshold and renal glucosuria occurs at higher than normal plasma glucose concentrations.

As a consequence, specific inhibition of the high capacity renal sodium-glucose co-transporter (SGLT-2) has emerged as a potential pharmacological intervention, which by decreasing tubular glucose reabsorption rates induces glucosuria and reduces blood glucose levels. In addition, continuous loss of calories in the urine is accompanied by a sustained decrease in body weight/fat in obese patients with type 2 diabetes. Initial observations in pre-clinical studies and in clinical trials have raised expectations for the utilization of SGLT-2 inhibitors in the treatment of type 2 diabetes. The data collected so far demonstrating a clinically significant glucose-lowering effect, body weight loss and negligible risk of hypoglycemia in patients treated with this novel class of drugs are very consistent.

The development of transient polyuria with dehydration and the occasional hypotension, particularly in elderly diabetic patients is of concern. The high frequency of urinary tract infections and genital mycosis requires close monitoring. Lower doses of SGLT-2 can be used safely in individuals with mild-to-moderate, but not in those with severe and end-stage renal insufficiency. Whether there is any long-term damage to the kidney is unknown and cardiovascular benefits are yet to be demonstrated with the use of these novel agents. Also, adverse effects on bone and mineral metabolism have not been sufficiently investigated. Some SGLT-2 inhibitors are now approved for the treatment of type 2 diabetes, either as monotherapy or in combination with other anti-diabetic medications. As long as patients can tolerate these agents, given all that we know today, SGLT-2 inhibitors if used with caution and in the proper patient may provide an additional safe and efficacious therapeutic option in the management of type 2 diabetes.

\section{REFERENCES}

1. Krebs HA, Hems RA, Gascoyne T. Renal gluconeogenesis. IV. Gluconeogenesis from substrate combinations. Acta Biol Med Ger 1963;11:607-15.

2. Cahill GF Jr. Starvation in man. N Engl J Med 1970;282:668-75. DOI: http://dx.doi.org/10.1056/NEJM197003192821209
3. Cersosimo E, Judd RL, Miles JM. Insulin regulation of renal glucose metabolism in conscious dogs. J Clin Invest 1994;93:2584-9. DOI: http://dx.doi.org/10.1172/JCI117270

4. Cersosimo E, Ajmal M, Naukam RJ, Molina PE, Abumrad NN. Role of the kidney in plasma glucose regulation during hyperglycemia. Am J Physiol 1997;272:E756-61. PMID: 9176172

5. Cersosimo E, Molina PE, Abumrad NN. Renal lactate metabolism and gluconeogenesis during insulin-induced hypoglycemia. Diabetes 1998;47:1101-6. DOI: http://dx.doi.org/10.2337/ diabetes.47.7.1101

6. Eid A, Bodin S, Ferrier B, Delage H, Boghossian M, Martin $\mathrm{M}$, et al. Intrinsic gluconeogenesis is enhanced in renal proximal tubules of Zucker diabetic fatty rats. J Am Soc Nephrol 2006;17:398-405. DOI: http://dx.doi.org/10.1681/ ASN.2005070742

7. Stumvoll M, Chintalapudi U, Perriello G, Welle S, Gutierrez O, Gerich J. Uptake and release of glucose by the human kidney. Postabsorptive rates and responses to epinephrine. J Clin Invest 1995;96:2528-33. DOI: http://dx.doi.org/10.1172/JCI118314

8. Cersosimo E, Garlick P, Ferretti J. Insulin regulation of renal glucose metabolism in humans. Am J Physiol 1999;276:E78-84. PMID: 9886953 DOI: http://dx.doi.org/10.2337/diabetes.48.2.261

9. Ekberg K, Landau BR, Wajngot A, Chandramouli V, Efendic $\mathrm{S}$, Brunengraber $\mathrm{H}$, et al. Contributions by kidney and liver to glucose production in the postabsorptive state and after 60 h of fasting. Diabetes 1999;48:292-8. DOI: http://dx.doi. org/10.2337/diabetes.48.2.292

10. Cersosimo E, Garlick P, Ferretti J. Abnormal glucose handling by the kidney in response to hypoglycemia in type 1 diabetes. Diabetes 2001;50:2087-93. DOI: http://dx.doi.org/10.2337/ diabetes.50.9.2087

11. Wirthensohn G, Guder WG. Renal substrate metabolism. Physiol Rev 1986;66:469-97. PMID: 2938198

12. Weidemann MJ, Krebs HA. The fuel of respiration of rat kidney cortex. Biochem J 1969;112:149-66. PMID: 5805283

13. Klein KL, Wang MS, Torikai S, Davidson WD, Kurokawa K. Substrate oxidation by isolated single nephron segments of the rat. Kidney Int 1981;20:29-35. PMID: 7300110 DOI: http:// dx.doi.org/10.1038/ki.1981.100

14. Guder WG, Ross BD. Enzyme distribution along the nephron. Kidney Int 1984;26:101-11. DOI: http://dx.doi.org/10.1038/ ki.1984.143

15. Wright EM. Renal $\mathrm{Na}(+)$-glucose cotransporters. Am J Physiol Renal Physiol 2001;280:F10-8. PMID: 11133510

16. Aronson PS, Sacktor B. The Na+ gradient-dependent transport of D-glucose in renal brush border membranes. J Biol Chem 1975;250:6032-9. PMID: 1150669

17. Turner RJ, Moran A. Heterogeneity of sodium-dependent D-glucose transport sites along the proximal tubule: evidence from vesicle studies. Am J Physiol 1982;242:F406-14. PMID: 6278960

18. Hediger MA, Coady MJ, Ikeda TS, Wright EM. Expression cloning and cDNA sequencing of the $\mathrm{Na}+$ /glucose co-transporter. Nature 1987;330:379-81. PMID: 2446136 DOI: http://dx.doi. org/10.1038/330379a0

19. Sacktor B. Sodium-coupled hexose transport. Kidney Int 1989;36:342-50. PMID: 2687560 DOI: http://dx.doi. org/10.1038/ki.1989.202

20. Lee WS, Kanai Y, Wells RG, Hediger MA. The high affinity $\mathrm{Na}+$ /glucose cotransporter. Re-evaluation of function and distribution of expression. J Biol Chem 1994;269:12032-9. PMID: 8163506

21. Hediger MA, Rhoads DB. Molecular physiology of sodium-glucose cotransporters. Physiol Rev 1994;74:993-1026.

22. Mogensen CE. Maximum tubular reabsorption capacity for glucose and renal hemodynamcis during rapid hypertonic glucose infusion in normal and diabetic subjects. Scand J Clin Lab Invest 1971;28:101-9. PMID: 5093515 DOI: http://dx.doi. org/10.3109/00365517109090668 
23. Kanai Y, Lee WS, You G, Brown D, Hediger MA. The human kidney low affinity Na+/glucose cotransporter SGLT2. Delineation of the major renal reabsorptive mechanism for D-glucose. J Clin Invest 1994;93:397-404. PMID: 8282810 DOI: http:// dx.doi.org/10.1172/JCI116972

24. Dominguez JH, Camp K, Maianu L, Garvey WT. Glucose transporters of rat proximal tubule: differential expression and subcellular distribution. Am J Physiol 1992;262:F807-12. PMID: 1590425

25. Cahill GF Jr, Herrera MG, Morgan AP, Soeldner JS, Steinke J, Levy PL, et al. Hormone-fuel interrelationships during fasting. J Clin Invest 1966;45:1751-69. PMID: 5926444 DOI: http:/ dx.doi.org/10.1172/JCI105481

26. Owen OE, Felig P, Morgan AP, Wahren J, Cahill GF Jr. Liver and kidney metabolism during prolonged starvation. J Clin Invest 1969;48:574-83. PMID: 5773093 DOI: http://dx.doi. org/10.1172/JCI106016

27. Ganong WF. Review of medical physiology. $19^{\text {th }}$ ed. Stamford: Appleton \& Lange; 1999:667-95.

28. Mather A, Pollock C. Glucose handling by the kidney. Kidney Int Suppl 2011:S1-6. PMID: 21358696 DOI: http://dx.doi. org/10.1038/ki.2010.509

29. Santer R, Kinner M, Lassen CL, Schneppenheim R, Eggert P, Bald $\mathrm{M}$, et al. Molecular analysis of the SGLT2 gene in patients with renal glucosuria. J Am Soc Nephrol 2003;14:2873-82. DOI: http://dx.doi.org/10.1097/01.ASN.0000092790.89332.D2

30. Farber SJ. Berger EY, Earle DP. Effect of diabetes and insulin of the maximum capacity of the renal tubules to reabsorb glucose. J Clin Invest 1951;30:125-9. DOI: http://dx.doi.org/10.1172/ JCI102424

31. Rahmoune H, Thompson PW, Ward JM, Smith CD, Hong G, Brown J. Glucose transporters in human renal proximal tubular cells isolated from the urine of patients with non-insulin-dependent diabetes. Diabetes 2005;54:3427-34. DOI: http://dx.doi. org/10.2337/diabetes.54.12.3427

32. Rossetti L, Smith D, Shulman GI, Papachristou D, DeFronzo RA. Correction of hyperglycemia with phlorizin normalizes tissue sensitivity to insulin in diabetic rats. J Clin Invest 1987;79:1510-5. PMID: 3571496 DOI: http://dx.doi. org/10.1172/JCI112981

33. Oku A, Ueta K, Arakawa K, Ishihara T, Nawano M, Kuronuma $\mathrm{Y}$, et al. T-1095, an inhibitor of renal Na+-glucose cotransporters, may provide a novel approach to treating diabetes. Diabetes 1999;48:1794-800. DOI: http://dx.doi.org/10.2337/ diabetes.48.9.1794

34. Ehrenkranz JR, Lewis NG, Kahn CR, Roth J. Phlorizin: a review. Diabetes Metab Res Rev 2005;21:31-8. DOI: http:// dx.doi.org/10.1002/dmrr.532

35. Isaji M. Sodium-glucose cotransporter inhibitors for diabetes. Curr Opin Investig Drugs 2007;8:285-92.

36. Tsujihara K, Hongu M, Saito K, Kawanishi H, Kuriyama K, Matsumoto $\mathrm{M}$, et al. $\mathrm{Na}(+)$-glucose cotransporter (SGLT) inhibitors as antidiabetic agents. 4. Synthesis and pharmacological properties of 4'-dehydroxyphlorizin derivatives substituted on the B ring. J Med Chem 1999;42:5311-24. DOI: http://dx.doi. org/10.1021/jm990175n

37. Grempler R, Thomas L, Eckhardt M, Himmelsbach F, Sauer A, Sharp DE, et al. Empagliflozin, a novel selective sodium glucose cotransporter-2 (SGLT-2) inhibitor: characterisation and comparison with other SGLT-2 inhibitors. Diabetes Obes Metab 2012;14:83-90. DOI: http://dx.doi.org/10.1111/j.14631326.2011.01517.x

38. DeFronzo RA, Hompesch M, Kasichayanula S, Liu X, Hong Y, Pfister $\mathrm{M}$, et al. Characterization of renal glucose reabsorption in response to dapagliflozin in healthy subjects and subjects with type 2 diabetes. Diabetes Care 2013;36:3169-76. DOI: http://dx.doi.org/10.2337/dc13-0387
39. Polidori D, Sha S, Mudaliar S, Ciaraldi TP, Ghosh A, Vaccaro $\mathrm{N}$, et al. Canagliflozin lowers postprandial glucose and insulin by delaying intestinal glucose absorption in addition to increasing urinary glucose excretion: results of a randomized, placebo-controlled study. Diabetes Care 2013;36:2154-61. DOI: http://dx.doi.org/10.2337/dc12-2391

40. Jurczak MJ, Lee HY, Birkenfeld AL, Jornayvaz FR, Frederick DW, Pongratz RL, et al. SGLT2 deletion improves glucose homeostasis and preserves pancreatic beta-cell function. Diabetes 2011;60:890-8. DOI: http://dx.doi.org/10.2337/db10-1328

41. Komoroski B, Vachharajani N, Boulton D, Kornhauser D, Geraldes M, Li L, et al. Dapagliflozin, a novel SGLT2 inhibitor, induces dose-dependent glucosuria in healthy subjects. Clin Pharmacol Ther 2009;85:520-6. DOI: http://dx.doi. org/10.1038/clpt.2008.251

42. Liu JJ, Lee T, DeFronzo RA. Why Do SGLT2 inhibitors inhibit only $30-50 \%$ of renal glucose reabsorption in humans? Diabetes 2012;6:2199-204.

43. Bailey CJ, Gross JL, Pieters A, Bastien A, List JF. Effect of dapagliflozin in patients with type 2 diabetes who have inadequate glycaemic control with metformin: a randomised, double-blind, placebo-controlled trial. Lancet 2010;375:2223-33. PMID: 20609968 DOI: http://dx.doi.org/10.1016/S01406736(10)60407-2

44. Nauck MA, Del Prato S, Meier JJ, Durán-García S, Rohwedder K, Elze M, et al. Dapagliflozin versus glipizide as add-on therapy in patients with type 2 diabetes who have inadequate glycemic control with metformin: a randomized, 52-week, double-blind, active-controlled noninferiority trial. Diabetes Care 2011;34:2015-22. DOI: http://dx.doi.org/10.2337/dc11-0606

45. Abdul-Ghani MA, Norton L, DeFronzo RA. Efficacy and safety of SGLT2 inhibitors in the treatment of type 2 diabetes mellitus. Curr Diab Rep 2012;12:230-8. DOI: http://dx.doi. org/10.1007/s11892-012-0275-6

46. Tahrani AA, Barnett AH, Bailey CJ. SGLT2 inhibitors in the management of diabetes. Lancet Diabetes Endocrinol 2013;1:140-51 DOI: http://dx.doi.org/10.1016/S2213-8587(13)70050-0

47. Food and Drug Administration Advisory Committee (19 th $^{\text {th }}$ uly $2011 \& 21^{\text {st }}$ March 2013) [accessed online on several occasions]. Available from: http://www.fda.gov

48. Wilding JP, Norwood P, T'joen C, Bastien A, List JF, Fiedorek FT. A study of dapagliflozin in patients with type 2 diabetes receiving high doses of insulin plus insulin sensitizers: applicability of a novel insulin-independent treatment. Diabetes Care 2009;32:1656-62. DOI: http://dx.doi.org/10.2337/dc09-0517

49. Kipnes MS. Sodium-glucose co-transporter 2 inhibitor in the treatment of type 2 diabetes: a review of Phase II and III trials. Clin Invest 2011; 1:145-56. DOI: http://dx.doi.org/10.4155/ cli.10.12

50. Rosenstock J, Aggarwal N, Polidori D, Zhao Y, Arbit D, Usiskin K, et al.; Canagliflozin DIA 2001 Study Group. Dose-ranging effects of canagliflozin, a sodium-glucose cotransporter 2 inhibitor, as add-on to metformin in subjects with type 2 diabetes. Diabetes Care 2012;35:1232-8. DOI: http:// dx.doi.org/10.2337/dc11-1926

51. Nauck MA, Del Prato S, Meier JJ, Durán-García S, Rohwedder K, Elze M, et al. Dapagliflozin versus glipizide as add-on therapy in patients with type 2 diabetes who have inadequate glycemic control with metformin: a randomized, 52-week, double-blind, active-controlled noninferiority trial. Diabetes Care 2011;34:2015-22. DOI: http://dx.doi.org/10.2337/dc11-0606

52. Blonde L, Wilding JP, Chiasson J-L, Polidori D, Meininger G, Stein P. Prolonged use of dapagliflozin versus glipizide in obese type 2 diabetic patients. Abstract 1110-P. Presented at the $73^{\text {rd }}$ Annual Meeting of the American Diabetes Association, 14-18 June 2013; Chicago, IL. 
53. American Diabetes Association. Standards of medical care in diabetes--2013. Diabetes Care 2013;36:S11-66. DOI: http:// dx.doi.org/10.2337/dc13-S011

54. Schwartz SS. A practice-based approach to the 2012 position statement of the American Diabetes Association and the European Association for the Study of Diabetes. Curr Med Res Opin 2013;29:793-9. DOI: http://dx.doi.org/10.1185/03007995.201 3.798637

55. Handelsman Y, Mechanick JI, Blonde L, Grunberger G, Bloomgarden ZT, Bray GA, et al.; AACE Task Force for Developing Diabetes Comprehensive Care Plan. American Association of Clinical Endocrinologists Medical Guidelines for Clinical Practice for developing a diabetes mellitus comprehensive care plan. Endocr Pract 2011;17:1-53. DOI: http://dx.doi. org/10.4158/EP.17.S2.1

56. Bolinder J, Ljunggren Ö, Kullberg J, Johansson L, Wilding J, Langkilde AM, et al. Effects of dapagliflozin on body weight, total fat mass, and regional adipose tissue distribution in patients with type 2 diabetes mellitus with inadequate glycemic control on metformin. J Clin Endocrinol Metab 2012;97:1020-31. PMID: 22238392 DOI: http://dx.doi.org/10.1210/jc.2011-2260
57. Woo V, Davis M, De Zeeuw D, Bakris G, Perkovic V, Gassmann-Mayer $\mathrm{C}$, et al. Change in HbA1c with canagliflozin in subjects with T2DM and Stage 3 Chronic Kidney Disease. Abstract 73-LB. Presented at the $73^{\text {rd }}$ Annual Meeting of the American Diabetes Association, 14-18 June 2013; Chicago, IL.

58 . Knochel JP. The syndrome of hyporeninemic hypoaldosteronism. Annu Rev Med 1979;30:145-53. DOI: http://dx.doi. org/10.1146/annurev.me.30.020179.001045

59. Chen J, Williams S, Ho S, Loraine H, Hagan D, Whaley JM, et al. Quantitative PCR tissue expression profiling of the human SGLT2 gene and related family members. Diabetes Ther 2010;1:57-92. DOI: http://dx.doi.org/10.1007/s13300010-0006-4

60. Santer R, Calado J. Familial renal glucosuria and SGLT2: from a mendelian trait to a therapeutic target. Clin J Am Soc Nephrol 2010;5:133-41. DOI: http://dx.doi.org/10.2215/ CJN.04010609 